\title{
Postnatal growth outcomes and influence of maternal gestational weight gain: a prospective cohort study in rural Vietnam
}

\author{
Sarah Hanieh ${ }^{1 *}$, Tran T Ha ${ }^{2}$, Julie A Simpson ${ }^{3}$, Tran T Thuy ${ }^{2}$, Nguyen C Khuong ${ }^{4}$, Dang D Thoang ${ }^{4}$, Thach D Tran ${ }^{2,5}$,
} Tran Tuan ${ }^{2}$, Jane Fisher ${ }^{5}$ and Beverley-Ann Biggs ${ }^{1,6}$

\begin{abstract}
Background: Suboptimal weight gain during pregnancy may result in adverse outcomes for both the mother and child, including increased risk of pre-eclampsia and gestational diabetes, delivery of low birth weight and small-for-gestational age (SGA) infants, and preterm delivery. The objectives of this study were to identify maternal predictors of rate of weight gain in pregnancy, and to evaluate the association of gestational weight gain with infant postnatal growth outcomes.

Methods: We conducted a prospective cohort study of infants born to women who had previously participated in a double-blind cluster randomized controlled trial of antenatal micronutrient supplementation, in Ha Nam province, Vietnam. Pregnant women $(n=1258)$ were seen at enrolment and 32 weeks gestation, and infants $(n=965)$ were followed until 6 months of age. Primary outcome was infant anthropometric indicators at 6 months of age (weight for age, length for age, weight for height z scores), and infant weight gain velocity during the first 6 months of life.

Results: Low body mass index $\left(<18.5 \mathrm{~kg} / \mathrm{m}^{2}\right)$ was present in $26 \%$ of women, and rate of gestational weight gain was $0.4 \mathrm{~kg}$ per week [SD 0.12]. Rate of weight gain during pregnancy was significantly associated with infant weight-for-age (MD 1.13, 95\% Cl 0.58 to 1.68), length-for-age (MD 1.11,95\% Cl 0.66 to 1.55), weight-for-length z scores (MD 0.63, 95\% Cl 0.07 to 1.19), and infant weight gain velocity during the first 6 months of life (MD $93.6 \mathrm{~g}$ per month, 95\% Cl 8.2 to 179.0).

Conclusions: Rate of gestational weight gain is predictive of postnatal growth at six months of age in this setting. Public health programs should be targeted towards improving body mass index and weight gain in pregnant women in rural Vietnam.
\end{abstract}

Keywords: Gestational weight gain, Postnatal growth, Body mass index

\section{Background}

Women who enter pregnancy with a sub-optimal body mass index (BMI) and gain either too little or too much weight have an increased risk of delivery of low birth weight and small-for-gestational age (SGA) infants, intrauterine growth restriction, neonatal mortality, preterm delivery, still birth and congenital defects [1-6]. Limited studies have examined the effect of gestational weight gain extending past the neonatal period into infancy or childhood, and those that are available have been

\footnotetext{
*Correspondence: shanieh@unimelb.edu.au

'Department of Medicine, University of Melbourne, L 4 Clinical Science Building, Royal Melbourne Hospital, Parkville, Victoria 3050, Australia Full list of author information is available at the end of the article
}

conducted in high-income countries [7-10]. Mounting evidence suggests that growth patterns in early life reflect body composition in adulthood [11], and are associated with increased risk of metabolic syndrome and the development of chronic diseases such as hypertension, coronary heart disease, and high cholesterol [12-14].

Currently the recommended weekly weight gain during the second and third trimesters of pregnancy is 0.8 to $1 \mathrm{kgs} /$ week for women with a normal pre-pregnancy BMI $\left(18.5-24.9 \mathrm{~kg} / \mathrm{m}^{2}\right), 1$ to $1.3 \mathrm{kgs} /$ week for women who are underweight (pre-pregnancy $\mathrm{BMI}<18.5 \mathrm{~kg} / \mathrm{m}^{2}$ ), and 0.5 to $0.7 \mathrm{kgs} /$ week for women who are overweight (pre-pregnancy BMI $\geq 25 \mathrm{~kg} / \mathrm{m}^{2)}$ [15]. However these recommendations are based on data collected from 
developed countries, where the main focus is on the adverse consequences of excess weight gain during pregnancy.

In Vietnam, underweight prevalence remains significantly higher than in other South East Asian countries, with around $20 \%$ of women reported to have low BMI $\left(<18.5 \mathrm{~kg} / \mathrm{m}^{2}\right)$ [16]. Determining predictors of gestational weight gain, and its influence on early infant postnatal growth, would provide an opportunity to better understand the nutritional programming of body composition in resource poor settings. This may enable appropriate targeting of preventive measures in early or pre-pregnancy, to improve child growth and development and reduce disease risk in later life.

We therefore conducted a prospective cohort study in a rural province of Vietnam that aimed to identify maternal predictors of rate of weight gain in pregnancy, and to determine the influence of rate of weight gain during pregnancy on infant growth outcomes at birth and 6 months of age.

\section{Methods}

Study design

This was an observational cohort study of pregnant women who had previously participated in a double-blind cluster randomized controlled trial of antenatal micronutrient supplementation in rural Vietnam. All women and infants enrolled in the original cluster randomised trial (ACTNR 12610000944033) were eligible for enrolment in the study. Our primary outcomes of interest were infant anthropometric measures at 6 months of age: weight for age $\mathrm{z}$ scores (WAZ), length for age $\mathrm{z}$ scores (LAZ), weight for length $\mathrm{z}$ scores (WLZ), and infant weight gain velocity during the first 6 months of life. Secondary outcomes were birth weight, length, and head circumference.

\section{Study setting and participants}

The study was undertaken in $\mathrm{Ha}$ Nam province in northern Vietnam. Ha Nam has a population of approximately 820,100 people, with most residents still working in subsistence agriculture. Diet consists mainly of rice, with some vegetables and meat. In 2010, the average annual per capita income was \$ USD 800 [17].

Eligible participants were all women and infants previously enrolled in a cluster randomised trial which took place between 28th September 2010 and 8th Jan 2012. For the original cluster randomised trial, women were randomised to receive either (1) one tablet of iron-folic acid (IFA) taken daily (60 mg elemental iron $/ 0.4 \mathrm{mg}$ folic acid per tablet, 7 tablets per week); (2) one capsule of IFA taken twice a week (60 mg elemental iron /1.5 mg folic acid per capsule; 2 capsules per week); or (3) one capsule of multiple micronutrients $(\mathrm{MMN})$ taken twice a week (60 mg elemental iron/1.5 mg folic acid per capsule/ plus zinc $20 \mathrm{mg}$, iodine $300 \mathrm{ug}$, copper $4 \mathrm{mg}$, selenium $130 \mathrm{ug}$, niacin $36 \mathrm{mg}$, Vitamins A $1.6 \mathrm{mg}, \mathrm{B} 12.8 \mathrm{mg}, \mathrm{B} 22.8 \mathrm{mg}$, B12 5.2 ug, C 140 mg, D 400 IU, E 20 mg;2 capsules per week.) Supplements were taken from enrolment until 3 months post-partum and primary outcome was infant birthweight. Each woman was visited every 6 weeks at home, to distribute the intervention with written instructions for the next 6 weeks, and to collect information on adherence, side effects, and pregnancy complications. The median level of adherence was $91 \%$ in the daily IFA group, $96 \%$ in the twice weekly IFA group, and $85 \%$ in the twice weekly MMN group. Adherence was verified with direct questioning, and by checking the number of tablets remaining. This trial has been previously published [18].

\section{Data collection and outcomes}

Rate of weight gain during pregnancy was derived from weight measurements taken at enrolment (range 2-16 weeks; mean gestational age 12.2 weeks) and at 32 weeks gestation (range 31-39 weeks; mean gestational age 33.4 weeks), divided by the number of weeks between the two observations. Infants were seen at birth and 6 months of age.

\section{Maternal characteristics}

Maternal sociodemographic factors were assessed using a questionnaire administered by trained research staff at enrolment. With early pregnancy (first trimester) dietary history, women were asked if they had changed their dietary habits (eating more vegetables, eating more nutritiously or eating larger quantities of food) on finding out they were pregnant. Meat intake (number of times per week) and use of prenatal nutritional or traditional supplementation were also recorded.

\section{Maternal anthropometric measurements}

Maternal height was measured with a portable stadiometer (Seca 214, Hamburg, Germany), and maternal weight with a mother-infant scale (Seca 872, Hamburg, Germany). BMI was calculated as weight in kilograms divided by height in metres squared. Mid upper arm circumference (MUAC) was measured using a flexible measuring tape at enrolment. Low mid upper arm circumference was defined as MUAC $<23.5 \mathrm{~cm}$ and short maternal stature was defined as height $<145 \mathrm{~cm}$.

\section{Infant anthropometric measurements}

Infant crown-heel length was measured using a portable Shorr Board (Shorr productions, Olney Md. USA), and weight was measured using electronic SECA 876 scales (SECA Ltd. Germany), with precision to the nearest $100 \mathrm{~g}$. Infant weight for age, weight for length and length for age $\mathrm{z}$ scores were calculated using WHO Anthro (version 3.2.2, January 2011) [19]. Stunting was defined as length-for-age $z$ 
scores less than two standard deviations below WHO Child Growth Standards, wasting as weight for length $\mathrm{z}$ scores less than two standard deviations below WHO Child Growth Standards, underweight as weight for age z scores less than two standard deviations below WHO Child Growth Standards, and low mid-upper arm circumference as mid upper arm circumference $\mathrm{z}$ scores less than two standard deviations below WHO Child Growth Standards [20]. Infant weight gain velocity was derived from weight measurements taken at birth and 6 months of age, divided by the number of months between the two observations.

\section{Gestational age}

Gestational age at birth was calculated from estimated gestational age recorded by trans-abdominal ultrasound performed at the district hospital if available (1041 (82.8\%) mothers), and if not, according to the date of last menstruation (136(10.8\%) mothers).

\section{Ethics considerations}

The study was approved by the Melbourne Health Human Research Ethics Committee, and the Hanam Provincial Human Research Ethics Committee. The original cluster randomised trial was registered in the Australia New Zealand Clinical Trials Registry: 12610000944033. Written informed consent was collected from all participants prior to enrolment.

\section{Statistical analysis}

Data were analysed using Stata, Version 12 (StataCorp, College Station, TX, USA). Categorical data are presented as percentages with frequency, and continuous data are presented as mean and standard deviation (SD). Univariable linear regression was performed to examine the association between 1) maternal factors (demographic, anthropometric, and antenatal factors) associated with rate of weight gain during pregnancy, and 2) the association between rate of weight gain during pregnancy and infant anthropometeric outcomes (birthweight, length, head circumference, WAZ, WHZ, HAZ scores and infant weight gain velocity at 6 months of age). Statistically significant predictors (defined as $\mathrm{p}<0.05$ in univariable analysis) were then selected for inclusion in a multivariable model along with potential confounding factors (. Unadjusted and adjusted estimates of mean differences or odds ratios, and their 95\% confidence intervals $(\mathrm{CI})$ are presented.

\section{Results}

The study flow diagram is presented in Figure 1. A total of 1258 pregnant women were enrolled into the original cluster randomised trial, 1042 women were seen at 32 weeks, and gestational rate of weight gain was available on 1041 women (82.8\%). 965 infants were seen at the 6 month visit. The three arms of the trial were equally represented among infants followed until 6 months of age. Twenty-six percent $(329 / 1257)$ of women were underweight at baseline $\left(\mathrm{BMI}<18.5 \mathrm{~kg} / \mathrm{m}^{2}\right)$, and $1.4 \%(18 / 1257)$ were classified as overweight $\left(\mathrm{BMI}>30 \mathrm{~kg} / \mathrm{m}^{2}\right)$. Average weekly weight gain was $0.4 \mathrm{~kg} /$ week [SD 0.13].

Baseline maternal characteristics according to baseline maternal BMI status are presented in Table 1. Mid upper arm circumference, meat intake during pregnancy and use of traditional supplements in early pregnancy were associated with maternal BMI at baseline.

\section{Factors associated with rate of weight gain during pregnancy}

Maternal factors associated with rate of weight gain during pregnancy were demographic: education (university/college educated vs primary school- MD $0.03 \mathrm{~kg} /$ week, 95\% CI 0.01 to 0.06), occupation (government worker vs farmer- MD $0.06 \mathrm{~kg} /$ week, $95 \%$ CI 0.03 to 0.09); taking over the counter nutritional supplements in early pregnancy $(0.02 \mathrm{~kg} /$ week, $95 \%$ CI 0.01 to 0.03$)$, and low mid upper arm circumference at baseline (MD $0.02 \mathrm{~kg} /$ week, $95 \%$ CI 0.01 to 0.03 ). The most commonly used over the counter supplements were iron supplements (71.4\%). Factors inversely associated with rate of weight gain during pregnancy included baseline BMI $(-0.01 \mathrm{~kg}$ per $\mathrm{kg} /$ week, 95\% CI -0.01 to -0.004$)$, and short maternal stature (MD $-0.05 \mathrm{~kg} /$ week, $95 \%$ CI -0.09 to -0.02 ) (Table 2).

\section{Association of rate of weight gain during pregnancy with infant birth outcomes}

Rate of gestational weight gain was significantly associated with infant birthweight (MD 532.3 gms, 95\% CI 339.8 to 724.9) and birth length (MD $2.41 \mathrm{~cm}, 95 \%$ CI 0.49 to 4.33 ), but not with head circumference (MD 0.35, 95\% CI -1.21 to 1.91) (Table 3).

\section{Association of rate of weight gain during pregnancy with infant anthropometric outcomes at 6 months of age}

Stunting prevalence was $6.4 \%$ at 6 months of age, and prevalence of wasting was less than $2 \%$. A significant association between rate of gestational weight gain and infant weight-for-age $(1.35,95 \%$ CI 0.78 to 1.92$)$, lengthfor-age $(1.18,95 \%$ CI 0.72 to 1.64$)$, and weight-for-length z scores (MD 0.84, 95\% CI 0.25 to 1.43 ) was demonstrated (Table 4).

\section{Association of rate of weight gain during pregnancy with infant weight gain velocity}

Mean infant weight gain velocity was 717.6 grams /month, SD [141.6]. For every $1 \mathrm{~kg} /$ week increase in weight gain during pregnancy, infant weight gain velocity increased by 93.6 grams per month (95\% CI 8.2 to 179.0$)$ during the first 6 months of life. 


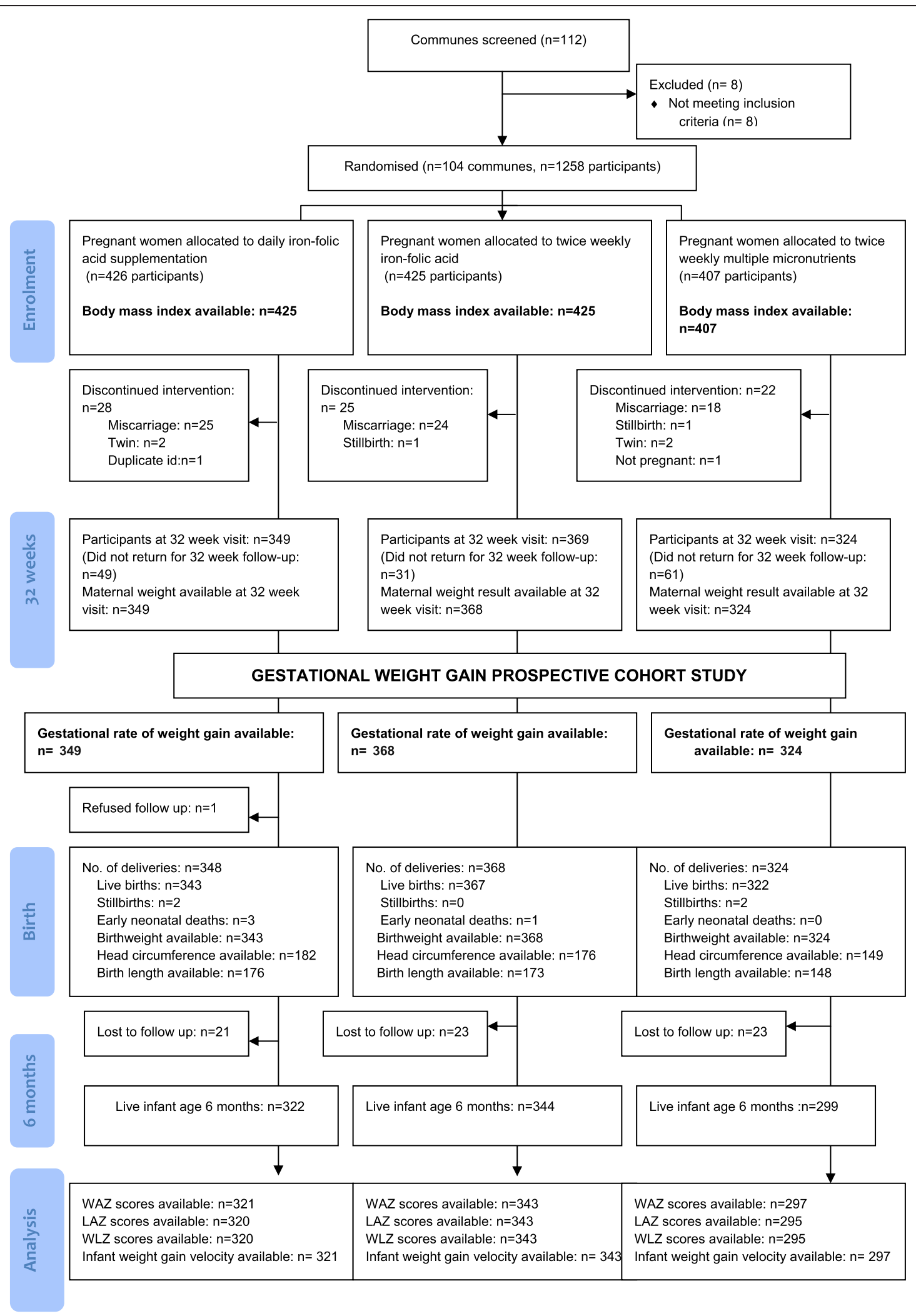

Figure 1 Flow diagram. 
Table 1 Baseline characteristics of pregnant women in rural Vietnam by grouping of BMI measurement at enrolment $\left(<18.5, \geq 18.5 \mathrm{~kg} / \mathrm{m}^{2}\right.$ )

\begin{tabular}{|c|c|c|c|c|c|c|c|}
\hline Maternal characteristic & $\begin{array}{l}\text { Total } \\
(n=1257)\end{array}$ & $\begin{array}{l}{[S D]} \\
\text { or }(\%)\end{array}$ & $\begin{array}{l}\text { Underweight } \\
\left.\text { (BMl }<18.5 \mathrm{~kg} / \mathrm{m}^{2}\right) \\
(\mathrm{n}=329)\end{array}$ & $\begin{array}{l}{[S D]} \\
\text { or }(\%)\end{array}$ & $\begin{array}{l}\text { Not underweight }{ }^{*} \\
\left(\mathrm{BMI}>=18.5 \mathrm{~kg} / \mathrm{m}^{2}\right) \\
(\mathrm{n}=928)\end{array}$ & $\begin{array}{l}{[S D]} \\
\text { or }(\%)\end{array}$ & $P$ valuet \\
\hline \multicolumn{8}{|l|}{ Demographic factors } \\
\hline Age (years) & 26.8 & {$[5.0]$} & 26.4 & {$[4.7]$} & 26.9 & {$[5.1]$} & 0.07 \\
\hline \multicolumn{8}{|l|}{ Educational level } \\
\hline Primary school & 160 & $(15.3)$ & 47 & $(14.3)$ & 151 & $(16.3)$ & 0.64 \\
\hline Secondary school & 705 & $(67.2)$ & 216 & $(65.6)$ & 603 & $(65.1)$ & \\
\hline University/college & 184 & $(17.5)$ & 66 & $(20.1)$ & 173 & $(18.7)$ & \\
\hline Occupation & & & & & & & 0.83 \\
\hline Farmer/housewife & 653 & $(52.0)$ & 168 & $(51.1)$ & 484 & $(52.2)$ & \\
\hline Factory worker/trader & 418 & (33.3) & 109 & $(33.1)$ & 309 & (33.3) & \\
\hline Government official/clerk & 186 & $(14.8)$ & 52 & $(15.8)$ & 134 & $(14.5)$ & \\
\hline \multicolumn{8}{|l|}{ Anthropometric factors } \\
\hline Height (cm) & 153.6 & {$[4.8]$} & 153.9 & {$[0.26]$} & 153.5 & {$[0.16]$} & 0.23 \\
\hline Mid upper arm circumference enrolment (cm) & 23.8 & {$[2.05]$} & 21.9 & {$[1.28]$} & 24.5 & {$[1.82]$} & $<0.001$ \\
\hline \multicolumn{8}{|l|}{ Antenatal factors } \\
\hline Gravidity & & & & & & & 0.21 \\
\hline Primigravida & 386 & $(30.7)$ & 110 & $(33.4)$ & 276 & $(29.7)$ & \\
\hline Multigravida & 871 & $(69.3)$ & 219 & $(66.6)$ & 652 & $(70.3)$ & \\
\hline Change of diet when pregnant & 941 & $(74.9)$ & 258 & $(78.4)$ & 683 & $(73.7)$ & 0.09 \\
\hline $\begin{array}{l}\text { Meat intake during pregnancy at enrolment } \\
\text { (no. of times per week) }\end{array}$ & 3.84 & {$[2.28]$} & 3.60 & [2.33] & 3.92 & {$[2.26]$} & 0.03 \\
\hline Use of nutritional supplements at baseline & 699 & $(55.6)$ & 190 & $(57.8)$ & 508 & $(54.8)$ & 0.36 \\
\hline Use of traditional supplements at baseline & 57 & $(4.5)$ & 22 & $(6.7)$ & 35 & (3.8) & 0.03 \\
\hline Depression EPDS & 235 & $(18.7)$ & 71 & $(21.6)$ & 164 & $(17.7)$ & 0.12 \\
\hline
\end{tabular}

*Values are mean or number.

tP value determined from chi squared or students t-test.

\section{Discussion}

Our findings indicate that rate of gestational weight gain was significantly associated with infant birth (weight and length) and growth outcomes at 6 months of age (weight for age, length for age, weight for length $\mathrm{z}$ scores weight gain velocity). We also documented a high prevalence of pregnant women residing in rural $\mathrm{Ha}$ Nam Province, Vietnam with a low BMI in early pregnancy. Maternal tertiary education and office-based occupation, as well as use of nutritional supplementation in early pregnancy predicted increased rate of weight gain during pregnancy. To our knowledge, this is the first study in a lower-income country to examine the influence of rate of gestational weight gain on postnatal growth outcomes.

Growth patterns in early infancy have been shown to make a significant contribution to body composition in later life, which may influence the future health and disease development in the child $[11,21]$. Previous studies have demonstrated that undernutrition during the in utero period can permanently change the physiology and composition of the body either through direct effects on the cell, or as a result of altered concentrations of growth factors, hormones, distribution of cell types, metabolic activity and organ structure. These changes can then in turn increase the risk of disease such as coronary heart disease, stroke, diabetes and hypertension in adult life [12,22-26].

The majority of previous studies in the literature have focussed on the association between weight gain during pregnancy and outcomes at birth [1-4,27-29]. Using data from seven population based cohort studies, Black et al. have shown that low maternal BMI during the pregnancy period significantly increases the risk of having a small for gestational age baby [30]. In a large cohort study in Vietnam, Ota et al. estimated the risk of giving birth to an infant too small or too large for gestational age as a function of maternal gestational weight gain and BMI, and demonstrated that a low maternal BMI and a weight gain of $<10 \mathrm{~kg}$ during pregnancy significantly increased the risk of delivering a small for gestational 
Table 2 Predictors of rate of weight gain (kg/week) during pregnancy (univariable and multivariable regression)

\begin{tabular}{|c|c|c|c|c|c|c|}
\hline \multirow[t]{2}{*}{ Maternal characteristic } & \multicolumn{3}{|c|}{ Univariable regression } & \multicolumn{3}{|c|}{ Multivariable regression* } \\
\hline & Coefficient & $(95 \% \mathrm{Cl})$ & $P$ value & Coefficient & $(95 \% \mathrm{Cl})$ & $P$ value \\
\hline \multicolumn{7}{|l|}{ Demographic factors } \\
\hline Maternal age (per 10 years) & -0.01 & $(-0.03$ to 0.01$)$ & 0.09 & & & \\
\hline \multicolumn{7}{|l|}{ Educational level } \\
\hline Primary school & Reference & & - & Reference & & - \\
\hline Secondary school & 0.01 & $(-0.01$ to 0.03$)$ & 0.50 & -0.01 & $(-0.02$ to 0.02$)$ & 0.93 \\
\hline University/College & 0.08 & (0.06 to 0.11$)$ & $<0.001$ & 0.03 & (0.004 to 0.06$)$ & 0.03 \\
\hline \multicolumn{7}{|l|}{ Occupation $^{2}$} \\
\hline Farmer/housewife & Reference & & - & Reference & & - \\
\hline Factory worker/trader & 0.01 & $(-0.01$ to 0.03$)$ & 0.24 & 0.01 & $(-0.01$ to 0.02$)$ & 0.61 \\
\hline Government official/clerk & 0.09 & (0.07 to 0.12$)$ & $<0.001$ & 0.06 & (0.03 to 0.09 ) & $<0.001$ \\
\hline \multicolumn{7}{|l|}{ Anthropometric factors } \\
\hline Low mid upper arm circumference $(<23.5 \mathrm{~cm})^{3}$ & 0.02 & (0.01 to 0.04$)$ & 0.01 & 0.02 & (0.01 to 0.03$)$ & 0.04 \\
\hline Maternal body mass index at enrolment $\left(\mathrm{kg} / \mathrm{m}^{2}\right)$ & -0.01 & $(-0.02$ to -0.04$)$ & $<0.001$ & -0.01 & $(-0.01$ to -0.004$)$ & 0.001 \\
\hline Short maternal stature (height < $145 \mathrm{~cm}$ ) & -0.05 & $(-0.10$ to -0.01$)$ & 0.02 & -0.05 & $(-0.09$ to -0.02$)$ & 0.01 \\
\hline \multicolumn{7}{|l|}{ Antenatal factors } \\
\hline \multicolumn{7}{|l|}{ Gravidity } \\
\hline Primigravida & Reference & & - & Reference & & - \\
\hline Multigravida & -0.03 & $(-0.05$ to -0.01$)$ & $<0.001$ & -0.01 & $(-0.03$ to 0.01$)$ & 0.21 \\
\hline Depression at enrolment (EPDS) & -0.01 & $(-0.03$ to 0.01$)$ & 0.54 & & & \\
\hline \multicolumn{7}{|l|}{ Nutritional factors } \\
\hline Taking nutritional supplementation & 0.04 & (0.03 to 0.06$)$ & $<0.001$ & 0.02 & (0.01 to 0.03$)$ & 0.03 \\
\hline Taking traditional supplements & -0.01 & $(-0.05$ to 0.03$)$ & 0.77 & & & \\
\hline $\begin{array}{l}\text { Meat intake during pregnancy at enrolment } \\
\text { (no. times per week) }\end{array}$ & 0.01 & (0.001 to 0.006$)$ & 0.09 & & & \\
\hline Change of diet in early pregnancy & 0.03 & (0.01 to 0.04$)$ & 0.01 & $0.01(-0.01$ to 0.03$)$ & & 0.05 \\
\hline \multicolumn{7}{|l|}{ Type of supplement taken during pregnancy } \\
\hline Daily IFA supplements & Reference & & - & Reference & & - \\
\hline Twice weekly IFA supplements & 0.01 & $(-0.02$ to 0.02$)$ & 0.83 & 0.01 & $(-0.02$ to 0.02$)$ & 0.93 \\
\hline MMN supplements & -0.01 & $(-0.03$ to 0.01$)$ & 0.31 & -0.01 & $(-0.02$ to 0.01$)$ & 0.59 \\
\hline
\end{tabular}

"Model adjusted for supplement group, gestational age at enrolment and cluster randomisation.

age baby [3]. Liu et al. found that women who were overweight/obese and had high weight gain, as well as those who were underweight and had a low weight gain, had a significantly higher risk of adverse pregnancy outcomes including large or small for gestational age, low birth weight and pre-eclampsia in a large cohort of singleton term pregnancies $(n=292,568)$ [31]. Our findings extend those of Heerman et al. who demonstrated that the combined effect of pre-pregnancy BMI and maternal gestational weight gain was significantly associated with infant growth trajectory

Table 3 Associations between rate of weight gain ( $\mathrm{kg} /$ week) during pregnancy and birth outcomes (univariable and multivariable regression)

\begin{tabular}{|c|c|c|c|c|c|c|c|c|}
\hline \multirow[t]{2}{*}{ Birth outcomes } & \multirow[b]{2}{*}{ Mean or number } & \multirow[b]{2}{*}{ [SD] or (\%) } & \multicolumn{3}{|l|}{ Unadjusted } & \multicolumn{3}{|l|}{ Adjusted $^{*}$} \\
\hline & & & Coefficient & $(95 \% \mathrm{Cl})$ & $P$ value & Coefficient & $(95 \% \mathrm{Cl})$ & $P$ value \\
\hline Birthweight (grams) & 3169.4 & {$[391.4]$} & 479.0 & (290.3 to 667.6) & $<0.001$ & 532.3 & (339.8 to 724.9$)$ & $<0.001$ \\
\hline Head circumference $(\mathrm{cm})$ & 32.7 & {$[2.11]$} & 0.38 & $(-1.17$ to 1.94$)$ & 0.63 & 0.35 & $(-1.21$ to 1.91$)$ & 0.66 \\
\hline Length (cm) & 49.1 & {$[2.59]$} & 2.29 & (0.38 to 4.20$)$ & 0.02 & 2.41 & (0.49 to 4.33$)$ & 0.02 \\
\hline
\end{tabular}

*Adjusted for maternal education, maternal body mass index, supplement arm, and cluster randomisation. 
Table 4 Associations between rate of weight gain (kg/week) during pregnancy and infant anthropometric outcomes (univariable and multivariable regression)

\begin{tabular}{|c|c|c|c|c|c|c|c|c|}
\hline \multirow[t]{2}{*}{ Anthropometric outcome at 6 months of age } & \multirow[b]{2}{*}{ Mean } & \multirow[b]{2}{*}{ [SD] } & \multicolumn{3}{|l|}{ Unadjusted } & \multicolumn{3}{|l|}{ Adjusted $^{*}$} \\
\hline & & & Coefficient & $(95 \% \mathrm{Cl})$ & $P$ value & Coefficient & $(95 \% \mathrm{Cl})$ & $P$ value \\
\hline Weight for age z score & -0.10 & {$[0.10]$} & 1.03 & (0.53 to 1.53$)$ & $<0.001$ & 1.35 & (0.78 to 1.92$)$ & $<0.001$ \\
\hline Weight for length z score & 0.40 & [1.01] & 0.51 & $(-0.01$ to 1.03$)$ & 0.05 & 0.84 & (0.25 to 1.43$)$ & 0.01 \\
\hline Length for age $z$ score & -0.57 & [0.92] & 1.09 & (0.63 to 1.56$)$ & $<0.001$ & 1.18 & (0.72 to 1.64$)$ & $<0.001$ \\
\hline Weight gain velocity (gm/month) & 717.6 & {$[141.6]$} & 79.0 & (7.32 to 150.8$)$ & 0.03 & 113.5 & (26.3 to 200.6) & 0.01 \\
\hline
\end{tabular}

*Adjusted for maternal education, maternal body mass index, supplement arm, gestational age at enrolment, wealth index and cluster randomisation.

throughout the first year of life [32]. We also demonstrated an inverse association between baseline maternal body mass index and rate of gestational weight gain, and this has also been shown by Rode et al. who found that gestational weight gain decreased with increasing body mass index [33].

Undernutrition at different times during the gestational period has been shown to result in varying effects on growth [12,22-25]. Barker et al. demonstrated that undernutrition during late gestation leads to disproportionate growth, whilst undernutrition during early gestation leads to proportionate loss of body size [22]. Disproportionate growth has been shown to result in an increased risk of coronary artery disease and other noncommunicable diseases [23]. Our findings strengthen the need for an urgent public health focus on improving the nutrition of pregnant women in Vietnam, and this is of particular importance in lower and middle income countries where overweight is an emerging problem and morbidity and mortality from non-communicable diseases is increasing [34].

In our study, we demonstrated a direct link between rate of weight gain during pregnancy and early infant weight gain velocity. Emerging evidence has shown that children who are undernourished or have poor weight gain during the first 2 years of life, are at significantly higher risk of chronic diseases in adulthood [14,35,36]. For example Hale et al. have previously proposed a thrifty 'phenotype hypothesis' where poor nutrition in fetal and early infant life predisposes to the later development of Type 2 diabetes through defects in the structure and function of Beta cells of the islets of Langerhans [37,38]. Further follow up of our cohort of infants beyond the early infancy period will therefore be important, to determine the long-term adverse consequences related to inadequate gestational weight gain in this setting.

We found that nearly $30 \%$ of women had low BMI in early pregnancy, which is an indicator of chronic energy deficiency and has been shown to be related to body fat mass and fat-free mass [39]. Although the prevalence of low maternal BMI has declined globally over the past twenty years, maternal under-nutrition is still of major concern in Asia and Africa [30]. Vietnam has achieved significant and rapid economic growth in the last decade, resulting in a reduction in the prevalence of the total population living under the poverty line, and a transformation in nutritional profile of the country [17]. Over the last two decades, a significant increase in the consumption of meat, total fat and eggs among the population has been documented, and underweight prevalence (BMI $<18.5 \mathrm{~kg} / \mathrm{m}^{2}$ ) in women aged $20-49$ years has reduced from $33.1 \%$ in 1990 to $20.5 \%$ in 2005 [16]. However, the rapid economic growth within the country has served to widen the socio-economic gap, with many of the rural population still facing significant inequities in economic, development and health burdens.

The strengths of our study are that infant anthropometric outcomes were followed past the neonatal period to six month of age, and that we measured BMI and weight gain directly, rather than rely on participant self-reporting as in many previous studies. In addition, our study was conducted in a rapidly developing rural area, representative of many areas of Vietnam, and thus our findings may be generalizable to other parts of the country.

Limitations of our study are that weight during pregnancy was only measured at enrolment and during late pregnancy (range 31-39 weeks; mean gestational age 33.4 weeks), and therefore we were unable to estimate total weight gain during pregnancy; and that maternal early pregnancy dietary habits were not accurately quantified. However despite this, the large sample size, and rigorous trial design of the original cluster randomised controlled trial, have allowed us to measure a comprehensive set of factors during the pregnancy period that predict rate of gestational weight gain, and to determine the critical influence of rate of weight gain during pregnancy on infant anthropometric outcomes.

\section{Conclusions}

Our findings highlight the important issue of low BMI in early pregnancy and the influence of gestational weight gain on infant outcomes in rural Vietnam. Rate of weight gain during pregnancy was found to be significantly associated with postnatal growth at six months of age, which may have adverse consequences for the infant that extend into 
childhood and beyond. Public health programs should be targeted towards improving nutritional status and weight gain in pregnant women in rural Vietnam.

\section{Competing interests}

The authors declare that they have no competing interests.

\section{Authors' contributions}

Study concept and design: SH, BAB, TTu, JF. Acquisition of data: TTHa, SH, TThu, NK. Analysis and interpretation of data: SH, TThu, JAS. Drafting of the manuscript: $\mathrm{SH}, \mathrm{BAB}$. Critical revision of the manuscript for important intellectual content: BAB, JAS. Statistical analysis: SH, JAS. Obtained funding: $B A B, J F, T T u$. Administrative, technical, and material support: $T T H a, T T r, T T u$, DT, NK. Study supervision: TTHa, SH, TThu, NK. All authors read and approved the final manuscript.

\section{Acknowledgements}

We thank the participants and health workers in Hanam province, the Hanam Provincial Centre of Preventive Medicine, Ministry of Health, RTCCD: Alfred Pathology; Beth Hilton-Thorp, and Christalla Hajisava for Department support.

\section{Author details}

${ }^{1}$ Department of Medicine, University of Melbourne, L 4 Clinical Science Building, Royal Melbourne Hospital, Parkville, Victoria 3050, Australia. ${ }^{2}$ Research and Training Centre for Community Development (RTCCD), Hanoi, Vietnam. ${ }^{3}$ Centre for Molecular, Environmental, Genetic and Analytic Epidemiology, Melbourne School of Population and Global Health, University of Melbourne, Parkville, Victoria, Australia. ${ }^{4}$ Provincial Centre of Preventive Medicine, Hanam Province, Vietnam. ${ }^{5}$ The Jean Hailes Research Unit, School of Public Health and Preventive Medicine, Monash University, Clayton, Victoria, Australia. ${ }^{6}$ The Victorian Infectious Diseases Service, Royal Melbourne Hospital, Parkville, Victoria, Australia.

Received: 8 July 2014 Accepted: 25 September 2014 Published: 30 September 2014

\section{References}

1. Drehmer M, Duncan BB, Kac G, Schmidt MI: Association of second and third trimester weight gain in pregnancy with maternal and fetal outcomes. PLoS One 2013, 8(1):e54704.

2. Durie DE, Thornburg LL, Glantz JC: Effect of second-trimester and thirdtrimester rate of gestational weight gain on maternal and neonatal outcomes. Obstet Gynecol 2011, 118(3):569-575.

3. Ota E, Haruna M, Suzuki M, Anh DD, le Tho H, Tam NT, Thiem VD, Anh NT, Isozaki M, Shibuya K, Ariyoshi K, Murashima S, Moriuchi H, Yanai H: Maternal body mass index and gestational weight gain and their association with perinatal outcomes in Viet Nam. Bull World Health Organ 2011, 89(2):127-136.

4. Radhakrishnan U, Kolar G, Nirmalan PK: Cross-sectional study of gestational weight gain and perinatal outcomes in pregnant women at a tertiary care center in southern India. J Obstet Gynaecol Res 2013, 40(1):25-31.

5. Black RE, Allen LH, Bhutta ZA, Caulfield LE, de Onis M, Ezzati M, Mathers C, Rivera J: Maternal and child undernutrition: global and regional exposures and health consequences. Lancet 2008, 371(9608):243-260.

6. Bhutta ZA, Das JK, Rizvi A, Gaffey MF, Walker N, Horton S, Webb P, Lartey A, Black RE: Evidence-based interventions for improvement of maternal and child nutrition: what can be done and at what cost? Lancet 2013, 382 (9890):452-477.

7. Deierlein AL, Siega-Riz AM, Adair LS, Herring AH: Effects of pre-pregnancy body mass index and gestational weight gain on infant anthropometric outcomes. J Pediatr 2011, 158(2):221-226.

8. Margerison-Zilko CE, Shrimali BP, Eskenazi B, Lahiff M, Lindquist AR, Abrams BF: Trimester of maternal gestational weight gain and offspring body weight at birth and age five. Matern Child Health J 2012, 16(6):1215-1223.

9. Margerison Zilko CE, Rehkopf D, Abrams B: Association of maternal gestational weight gain with short- and long-term maternal and child health outcomes. Am J Obstet Gynecol 2010, 202(6):574 e571-578.

10. Olson CM, Strawderman MS, Dennison BA: Maternal weight gain during pregnancy and child weight at age 3 years. Matern Child Health J 2009, 13(6):839-846.
11. Chandler-Laney PC, Gower BA, Fields DA: Gestational and early life influences on infant body composition at 1 year. Obesity (Silver Spring) 2013, 21(1):144-148.

12. Barker DJ: Fetal origins of coronary heart disease. BMJ 1995, 311(6998):171-174.

13. Hochner $H$, Friedlander $Y$, Calderon-Margalit $R$, Meiner V, Sagy Y, Avgil-Tsadok M, Burger A, Savitsky B, Siscovick DS, Manor O: Associations of maternal prepregnancy body mass index and gestational weight gain with adult offspring cardiometabolic risk factors: the Jerusalem Perinatal Family Follow-up Study. Circulation 2012, 125(11):1381-1389.

14. Victora CG, Adair L, Fall C, Hallal PC, Martorell R, Richter L, Sachdev HS: Maternal and child undernutrition: consequences for adult health and human capital. Lancet 2008, 371(9609):340-357.

15. Institute of Medicine of the National Academies: Weight Gain During Pregnancy: Reexamining the Guidelines. USA: National Academies Press; 2009.

16. Ha do TP, Feskens EJ, Deurenberg P, Mai le B, Khan NC, Kok FJ: Nationwide shifts in the double burden of overweight and underweight in Vietnamese adults in 2000 and 2005: two national nutrition surveys. BMC Public Health 2011, 11:62.

17. Viet Nam Academy of Social Science: Vietnam Poverty Update: Poverty and Poverty Reduction in Vietnam 1993-2004. Hanoi: Viet Nam Academy of Social Science; 2006

18. Hanieh S, Ha TT, Simpson JA, Casey GJ, Khuong NC, Thoang DD, Thuy TT, Pasricha SR, Tran TD, Tuan T, Dwyer T, Fisher J, Biggs BA: The effect of intermittent antenatal iron supplementation on maternal and infant outcomes in rural Viet Nam: a cluster randomised trial. PLoS Med 2013, 10(6):e1001470.

19. World Health Organisation: WHO Anthro, version 3.2.2 [computer program]. Geneva: World Health Organization; 2011.

20. The WHO Child Growth Standards. [http://www.who.int/childgrowth/en/]

21. Slining MM, Kuzawa CW, Mayer-Davis EJ, Adair LS: Evaluating the indirect effect of infant weight velocity on insulin resistance in young adulthood: a birth cohort study from the Philippines. Am J Epidemiol 2011, 173(6):640-648.

22. Barker DJ: The fetal and infant origins of disease. Eur J Clin Invest 1995, 25(7):457-463.

23. Barker DJ: Intrauterine programming of adult disease. Mol Med Today 1995, 1(9):418-423.

24. Barker DJ: The Wellcome Foundation Lecture, 1994. The fetal origins of adult disease. Proc Biol Sci 1995, 262(1363):37-43.

25. Dennison E, Fall C, Cooper C, Barker D: Prenatal factors influencing long-term outcome. Horm Res 1997, 48(Suppl 1):25-29.

26. Seremak-Mrozikiewicz A, Barlik M, Drews K: [Fetal programming as a cause of chronic diseases in adult life]. Ginekol Pol 2014, 85(1):43-48.

27. Watanabe $H$, Inoue $K$, Doi M, Matsumoto M, Ogasawara K, Fukuoka $H$, Nagai Y: Risk factors for term small for gestational age infants in women with low prepregnancy body mass index. J Obstet Gynaecol Res 2010, 36(3):506-512.

28. Li Y, Chen X, Chen S, Wu J, Zhuo X, Zheng Q, Wei X, Zhang R, Huang H, Zheng $C$, Lin J: [A cohort study on the impacts of pre-pregnancy maternal body mass index, gestational weight gain on neonate birth status and perinatal outcomes in Fujian province]. Zhonghua Liu Xing Bing Xue Za Zhi 2014, 35(6):635-640.

29. Jeric M, Roje D, Medic N, Strinic T, Mestrovic Z, Vulic M: Maternal prepregnancy underweight and fetal growth in relation to institute of medicine recommendations for gestational weight gain. Early Hum Dev 2013, 89(5):277-281.

30. Black RE, Victora CG, Walker SP, Bhutta ZA, Christian P, de Onis M, Ezzati M, Grantham-McGregor S, Katz J, Martorell R, Uauy R: Maternal and child undernutrition and overweight in low-income and middle-income countries. Lancet 2013, 382(9890):427-451.

31. Liu Y, Dai W, Dai X, Li Z: Prepregnancy body mass index and gestational weight gain with the outcome of pregnancy: a 13-year study of 292,568 cases in China. Arch Gynecol Obstet 2012, 286(4):905-911.

32. Heerman WJ, Bian A, Shintani A, Barkin SL: Interaction between maternal prepregnancy body mass index and gestational weight gain shapes infant growth. Acad Pediatr 2014, 14(5):463-470.

33. Rode L, Kjaergaard H, Ottesen B, Damm P, Hegaard HK: Association between gestational weight gain according to body mass index and postpartum weight in a large cohort of Danish women. Matern Child Health J 2012, 16(2):406-413.

34. Lozano R, Naghavi M, Foreman K, Lim S, Shibuya K, Aboyans V, Abraham J, Adair T, Aggarwal R, Ahn SY, Alvarado M, Anderson HR, Anderson LM, 
Andrews KG, Atkinson C, Baddour LM, Barko-Collo S, Bartels DH, Bell ML, Benjamin EJ, Bennett D, Bhalla K, Bikbov B, Bin Abdulhak A, Birbek G, Blyth F, Bolliger I, Bourfous S, Bucello C, Burch M, et al: Global and regional mortality from 235 causes of death for 20 age groups in 1990 and 2010: a systematic analysis for the Global Burden of Disease Study 2010. Lancet 2012, 380(9859):2095-2128.

35. Eriksson JG, Forsen T, Tuomilehto J, Osmond C, Barker DJ: Early growth and coronary heart disease in later life: longitudinal study. BMJ 2001,

322(7292):949-953.

36. Fisher D, Baird J, Payne L, Lucas P, Kleijnen J, Roberts H, Law C: Are infant size and growth related to burden of disease in adulthood? A systematic review of literature. Int J Epidemiol 2006, 35(5):1196-1210.

37. Hales CN, Barker DJ: Type 2 (non-insulin-dependent) diabetes mellitus: the thrifty phenotype hypothesis. Diabetologia 1992, 35(7):595-601.

38. Hales CN, Barker DJ, Clark PM, Cox LJ, Fall C, Osmond C, Winter PD: Fetal and infant growth and impaired glucose tolerance at age 64. BMJ 1991, 303(6809):1019-1022.

39. Norgan NG: Body mass index and body energy stores in developing countries. Eur J Clin Nutr 1990, 44(Suppl 1):79-84.

doi:10.1186/1471-2393-14-339

Cite this article as: Hanieh et al:: Postnatal growth outcomes and influence of maternal gestational weight gain: a prospective cohort study in rural Vietnam. BMC Pregnancy and Childbirth 2014 14:339.

\section{Submit your next manuscript to BioMed Central and take full advantage of:}

- Convenient online submission

- Thorough peer review

- No space constraints or color figure charges

- Immediate publication on acceptance

- Inclusion in PubMed, CAS, Scopus and Google Scholar

- Research which is freely available for redistribution 